\title{
Influences of Hybrid Cooling Mechanism through PV System under Solar Simulator Testing
}

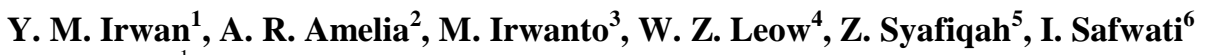 \\ ${ }^{1}$ Centre for Diploma Studies, University Malaysia Perlis, Malaysia. \\ ${ }^{1,2,3,4,5}$ Centre of Excellence for Renewable Energy, School of Electrical System Engineering, University Malaysia Perlis \\ Malaysia \\ ${ }^{3}$ Department of Electrical Engineering, Medan of Institute of Technology, Indonesia \\ ${ }^{6}$ Institute of Engineering Mathematics, University Malaysia Perlis, Malaysia
}

\section{Article Info}

Article history:

Received Jun 7, 2017

Revised Aug 17, 2017

Accepted Aug 23, 2017

\section{Keyword:}

Direct-current (DC) fan Photovoltaic (PV) panel PV panel temperature

Solar radiation

Solar simulator

Water-pump

\begin{abstract}
An increasing efficiency of the solar system can be improved by using hybrid cooling mechanism. This paper presents the impact of hybrid cooling mechanism on PV panel under indoor testing with varying solar intensity. Thus, the fabrication of a solar simulator for indoor testing reacts as the space solar radiation is described. The performance of PV panel which attached to a hybrid cooling mechanism compared with PV panel without cooling mechanism under variation of average solar radiation. Experimental tests were carried out for various average solar radiations by varying the number of lamps and/or the lamp-to-area distance. Without altering the spectral distribution, the characteristic of current-voltage of PV panel was analysed under average solar radiation which varied from $202 \mathrm{~W} / \mathrm{m}^{2}$ to 1003 $\mathrm{W} / \mathrm{m}^{2}$. As the result, the PV panel with hybrid cooling system explored to generate more power output with decreasing in PV panel temperature. About $15.79 \%$ increment of power output generated by PV panel with cooling at maximum average solar radiation. Furthermore, the PV panel temperature also can be decreased about $10.28 \%$ respectively. The combination of DC fan and water pump as cooling mechanism plays an important role in generating efficient power output from PV panel.
\end{abstract}

Copyright @ 2017 Institute of Advanced Engineering and Science. All rights reserved.

\section{Corresponding Author:}

A. R. Amelia,

Centre of Excellence for Renewable Energy,

School of Electrical System Engineering,

University Malaysia Perlis (UniMAP), Malaysia.

Email: amelia_razak87@yahoo.com

\section{INTRODUCTION}

Solar energy is one of the most important sources of renewable energy become one of the most desirable applications to reduce energy consumption [1]. PV panel is commonly known as one of the promising compartments of solar energy technologies. It is a well-known fact that the electrical efficiency of PV panel falls as the temperature of the photovoltaic cells arise. From the radiation falling onto a PV panel only up to $20 \%$ of the incident solar energy is converted to electricity [2]. Basically, more heat energy will produce compared to electrical energy with absorption of solar radiation. The existing heat energy leads increasing temperature through PV panel. The efficient output energy of solar system generated at high solar radiation with low temperature. Hence, cooling technology represented as a proposed method of keeping the PV panel operated at low temperature.

PV panel suffers from a drop in efficiency with the rise in temperature due to heat energy generated. The increase in operating PV temperature consequently decreasing the efficient conversion of electricity. Thus, the effectiveness of a PV system can be produced by carrying heat away from the PV panel with cool 
down it. A lot of researchers have worked on some techniques, like air cooling and water cooling, are utilized to cool the PV panel to maintain lower operating temperature. In a number of studies, water being the most favourite as working fluid used among researcher to cool down PV panel [3-6]. There is a higher potential for heat production than electricity from a given surface of a PV module. By water flow over the front side of PV panel, it's not only decreasing PV temperatures, instead reduced reflection loss and keeping the surface clean. As regards air as the working fluid, many experimental studies used fan to cool down the backside of PV module [7-8]. Cooling fan define as a force convection method will force cool air from outside flow through PV panel to extract heat produced. The hot air distributed inside PV panel will cool down with existing high density cool air from outside. Therefore, in this experimental study, the combination of water-air (fan) are produced to cool down back and front side of PV panel.

The performance of PV panel varies with environmental atmospheric, especially with solar radiation and ambient temperature [9-11]. To explore in details the effect of hybrid cooling system on PV panel, an indoor testing using a solar simulator shall be used to obtain a steady state performance of a PV panel. The development of solar simulator enables to carry out experimental testing PV panel without the exposure to the outdoor weather fluctuations. Besides, test experimental also can be carried out at any chosen time and the surrounding environment can be controlled practically with existing simulator. Solar simulator is an integral part of any laboratory involved light as a source to simulates solar radiation. The operation of the solar simulator mainly depends on the suitable light source to simulate sunlight intensity. Variation lamps have been proposed such as a metal halide arc lamp, xenon arc lamp, mercury xenon lamp, and light-emitting diode lamp (LED).

M. Shatat et al. developed a novel solar simulator by using $400 \mathrm{~W}$ of halogen lamps. 30 units of halogen lamps are represented to cover a gross area of $2.32 \mathrm{~m}^{2}$. Various levels of solar intensity started from $245 \mathrm{~W} / \mathrm{m}^{2}$ to $850 \mathrm{~W} / \mathrm{m}^{2}$ was carried out by the authors in order to analyse the performance of an evacuated solar collector [12]. LED lamps have been used as light sources in developed small solar simulator for solar cell measurements [13]. In this paper, about 3\% of the unevenness has been found in testing small areas of $100 \times 100 \mathrm{~mm}^{2}$ of photovoltaic cells. S. Agrawal et al. S. Agrawal et al. evaluated the performance of microchannel solar cell thermal (MCSCT) in terms of electrical efficiency, thermal gain and overall thermal energy in indoor conditions. About 28 units of $500 \mathrm{~W}$ tungsten halogen lamps act as radiation sources in developing solar simulator. The intensity of radiation has been varied between $300 \mathrm{~W} / \mathrm{m}^{2}$ to $1000 \mathrm{~W} / \mathrm{m}^{2}$ by decreasing gap between of halogen lamps and platform [14]. M.G. Guvench et al. carried out I-V measurements for solar testing. The optimal operational points for maximum electrical output were determined under solar simulator. A solar simulator has been developed by combining metal-halide and quartz halogen as light sources [15]. Under indoor testing, Irwan et al. developed a solar simulator due to analyse the performance of PV panels with or without cooling mechanism. An experimental conducted under four sets of uniformity of solar radiation which are $413,620,821$ and $1016 \mathrm{~W} / \mathrm{m}^{2}$. The results observed that there is decrease in temperature with $2-3{ }^{\circ} \mathrm{C}$ when using the air cooling mechanism. Reducing in temperature causes the increament in power output with the range of 6-14\% respectively [16].

In this present study, a solar simulator has been developed due to investigate the impact of hybrid cooling system on PV panel. The hybrid cooling mechanism consists of water spraying over the front side surface where two units DC fan used to extract heat produced at the backside the PV panel. About 20 units of $500 \mathrm{~W}$ halogen lamps used as light source in developed solar simulator. The main focus is on the comparison of the PV panel with and without cooling mechanism under some selected of average solar intensity.

\section{DEVELOPMENT OF HALOGEN LAMP ARRAY AS SOLAR SIMULATOR}

A solar simulator is invaluable for a solar energy laboratory that closely simulate the sun's spectra with good uniformity. The main compartment of the solar simulator can be classified into two subsystems which are light source and adjustment structure. Figure 1 (a) presents the schematic of the experimental setup of the halogen lamp array as the purpose to distribute solar simulator. The fabricated solar simulator consists of 20 units of halogen lamp with built in reflector. All halogen lamps are arranged in a 4 x 5 metrics for uniform distribution of solar radiation for PV panels used. The halogen lamps are positioned in 4 rows which consisting of 5 lamps each. The distance between the centers of each halogen lamp is approximately $32 \mathrm{~cm}$. Figure 1 (b) shows a metal support structure made of steel with a size of $183 \mathrm{~cm}$ by $183 \mathrm{~cm}$ by $183 \mathrm{~cm}$ is used to hold all the halogen lamps. Metal steel is fabricated with a mechanism for up and down movement. The maximum height of the simulator from the floor is $183 \mathrm{~cm}$. The distance between the PV panel surface and halogen lamp is $100 \mathrm{~cm}$.

The physical dimension of halogen lamp used is illustrated as in Figure 1 (c). Table 1 describes the specification of halogen lamp used in this study. The maximum electrical power consumed by each lamp is $500 \mathrm{~W}$. The solar simulator has 20 units of halogen lamp each having 9660 Lumens and rated at $230 \mathrm{~V}$ and 
2.17 A. In addition, the lifespan of the lamps is 2000 hours with less expensive to purchase and have the ability to operate at high temperatures. These lamps are widely used in the solar beam experiment (SBE) for solar simulator applications because it provides a very stable and smooth spectral output [14].

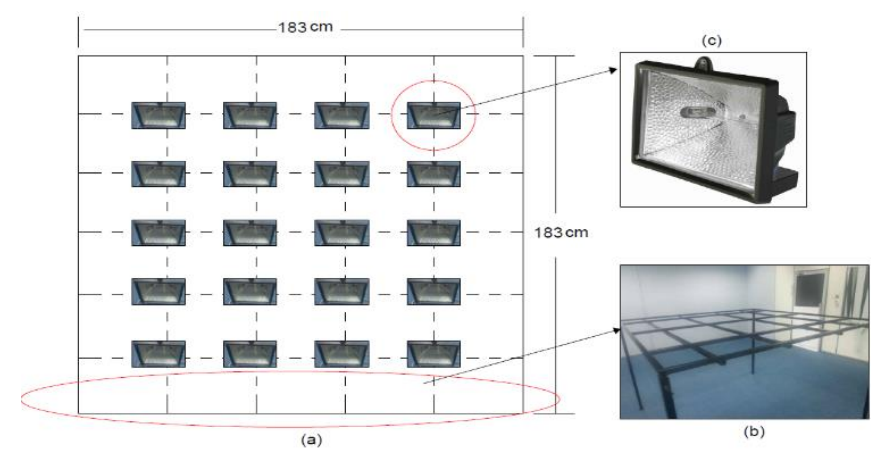

Figure 1. (a) Layout of the Halogen Lamps Array, (b) Horizontal Adjusted Steel Metal Structure, (c) Halogen Lamp

Table 1. Specification of Halogen Lamp

\begin{tabular}{cc}
\hline Parameter & Operation \\
\hline Model & Philips \\
Wattage & $500 \mathrm{~W}$ \\
Voltage & $230 \mathrm{~V}$ \\
Current & $2.17 \mathrm{~A}$ \\
Lifetime & $2000 \mathrm{hr}$ \\
Illumination & $9660 \mathrm{Lm}$ \\
Size & $250 \times 183 \mathrm{~mm} \mathrm{x} 103 \mathrm{~mm}$ \\
\hline
\end{tabular}

\section{DEVELOPMENT OF HYBRID COOLING MECHANISM THROUGH PV PANEL}

A hybrid cooling mechanism was installed to investigate the overall electrical performance of PV panel. The cooling mechanism fabricated by combining DC fan and water as cooling mechanism. A combination between both cooling mediums illustrated as shown in Figure 2. This cooling fabrication was designed to observe how the cooling mechanism reduced the PV panel temperature, which has great influence on the output performance PV panel during operation. Figure 2 (a) observed the water spraying over the front surface of PV panel. The tube pipe is attached to the rear side of the PV panel and equipped with an inlet/outlet port for the water flow. In addition, the required water for spraying is fed by the water pump. Not only as the coolant, water has capability to reduce reflection loss as well as clean the surface of PV panel. The inlet/outlet manifold of DC fan attached at the back side of PV panels is shown in Figure 2 (b). Two units of DC fan were installed together with zinc steel which also classified as heat transfer material. Air flow from outside will flow through inside manifold then extract heat distributed throughout outlet manifold as well as reduced the temperature.

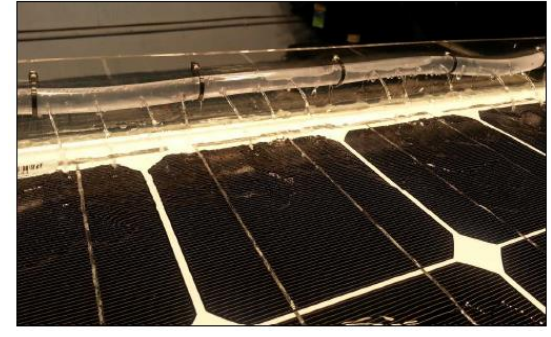

(a)

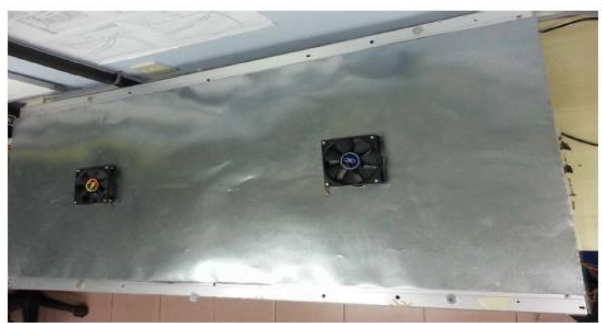

(b)

Figure 2. (a) Water spray over the front side of PV panel and (b) inlet/outlet manifold DC fans attached at the back side of a PV panel 


\section{METHODOLOGY AND TEST PROCEDURE}

The experimental procedure conducted by comparing the overall performance through PV panel without and with cooling mechanism. Figure 3 shows the overall test setup. Two units of $50 \mathrm{~W}$ mococrystalline PV panel were tested together with a different set up. One of the PV panels is attached to a hybrid cooling mechanism instead the other one act as a PV reference panel. The overall electrical performance, such as current, voltage and power output were measured using PROVA 200 solar panel analyzer for both PV panels. TES solar power meter manufactured by TES Electrical Electronic Corp was used to measure the solar radiation of the solar simulator at the test surface. The radiation was measured 10 times at the same height of metal steel structure to produce the average measurement. Five sets of average solar radiation were measured at different height as $202 \mathrm{~W} / \mathrm{m}^{2}, 408 \mathrm{~W} / \mathrm{m}^{2}, 616 \mathrm{~W} / \mathrm{m}^{2}, 805 \mathrm{~W} / \mathrm{m}^{2}$, and 1003 $\mathrm{W} / \mathrm{m}^{2}$. In purpose to observe the temperature distribution due to various solar radiations, each PV panel was attached with four units of thermocouple-K at the backside their surface.

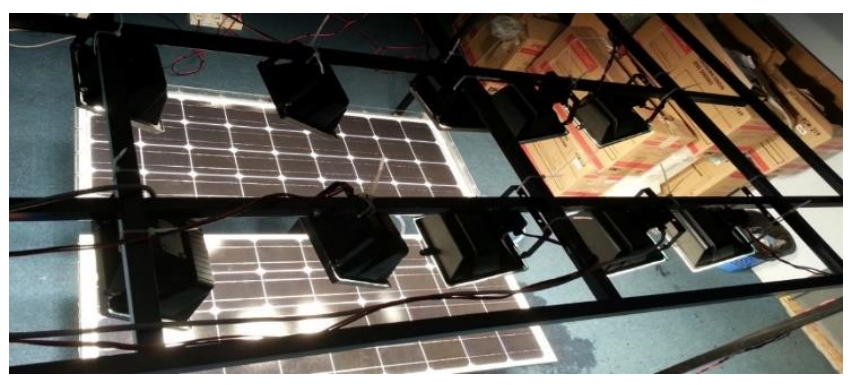

Figure 3. The Overall Experimental Setup

\section{RESULTS AND DISCUSSIONS}

In an experiment conducted, all data have been collected and recorded at different solar intensity for comparative evaluation for both PV panel. The performance of both PV panels was compared based on their temperature distribution and electrical output power.

\subsection{Solar Radiation Versus Horizontal Height of Halogen Lamp Array}

Various solar intensity will be produced due to analyze the impact off cooling mechanism. The level of solar radiation adjusted by decreasing/increasing the number of a halogen lamp. Few lamps will be switched on, while others are switched off in order to achieve a required point of solar radiation. Other, the variation solar radiation also can be produced by adjusting the height of the metal steel support structure. The metal steel structure is independently horizontally adjusted. Table 2 presents five sets average of solar radiation were measured. Continuous observations simplified that the solar simulator took 10-20 minutes to reach a constant intensity for every level radiation adjusted. The maximum average solar radiation found at height metal steel structure of $68.11 \mathrm{~cm}$ with $1003 \mathrm{~W} / \mathrm{m}^{2}$ solar radiation. By further increasing the gap between halogen lamp array and PV panel surface from $84.31 \mathrm{~cm}$ to $94 \mathrm{~cm}, 120.32 \mathrm{~cm}$ and $139.98 \mathrm{~cm}$, the average solar radiation decreased to $805 \mathrm{~W} / \mathrm{m}^{2}, 616 \mathrm{~W} / \mathrm{m}^{2}, 408 \mathrm{~W} / \mathrm{m}^{2}$, and $202 \mathrm{~W} / \mathrm{m}^{2}$ respectively.

Table 2. Distance between Halogen Lamp Array and PV Panel Surface

\begin{tabular}{cc}
\hline Average solar radiation & $\begin{array}{c}\text { Distance between halogen lamp } \\
\text { array and PV panel surface }\end{array}$ \\
\hline $202 \mathrm{~W} / \mathrm{m}^{2}$ & $139.98 \mathrm{~cm}$ \\
$408 \mathrm{~W} / \mathrm{m}^{2}$ & $120.32 \mathrm{~cm}$ \\
$611 \mathrm{~W} / \mathrm{m}^{2}$ & $94.00 \mathrm{~cm}$ \\
$805 \mathrm{~W} / \mathrm{m}^{2}$ & $84.31 \mathrm{~cm}$ \\
$1003 \mathrm{~W} / \mathrm{m}^{2}$ & $68.11 \mathrm{~cm}$ \\
\hline
\end{tabular}

\subsection{Temperature Distribution through PV Panels}

PV panel temperature is a parameter that has great influence in assessing the long term performance of PV panels, as it modifies system efficiency and output energy. When exposed to the sun, the PV panel temperature is normally greater than the ambient temperature. The ambient temperature normally affected by the potential of solar radiation as shown in the Figure 4. In this figure, it describes a high solar radiation will 
produce a high ambient temperature. The average maximum ambient temperature distributed at $1003 \mathrm{~W} / \mathrm{m}^{2}$ solar radiation with $40.54{ }^{\circ} \mathrm{C}$. Whereas the average minimum ambient temperature with average of solar radiation at $202 \mathrm{~W} / \mathrm{m}^{2}$ with $32.4^{\circ} \mathrm{C}$. As known, the temperature of $\mathrm{PV}$ panel does not keep constant during experimental. It keeps changing depending on the intensity of solar radiation. With existing of solar simulator, the impact of solar radiation on ambient temperature can be discussed. Ike and C.U indicated that the maximum values of high ambient temperature due to experience in high solar radiation [17].

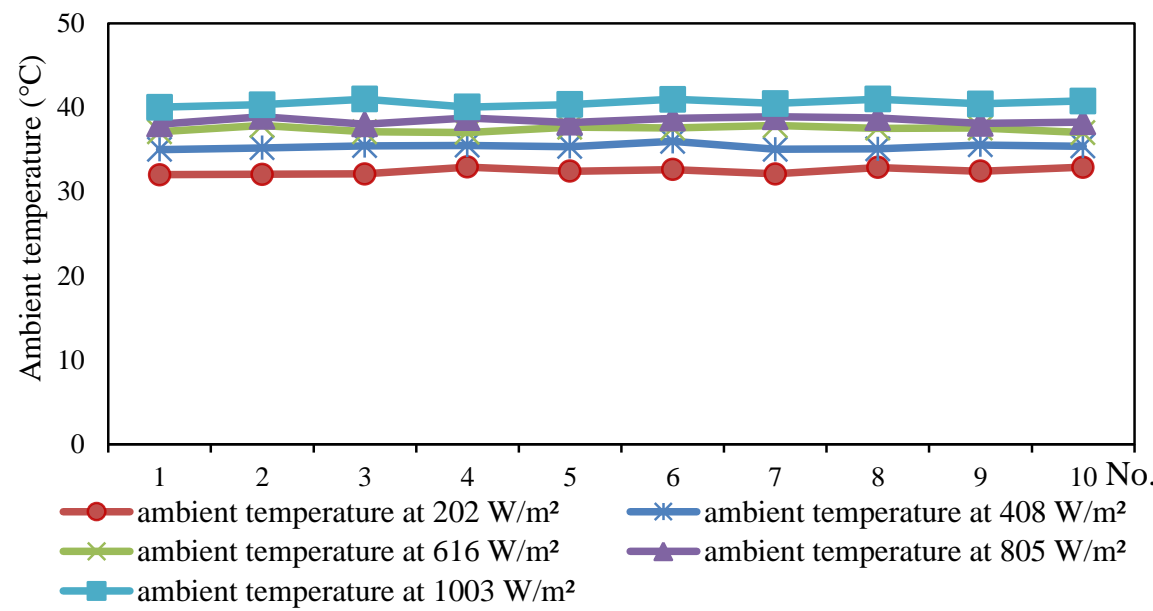

Figure 4. Ambient Temperature Versus Solar Radiation

Figure 5 presents the comparative temperature distribution between PV panel without and with cooling system under various average of solar radiation. As shown in this figure, by using a hybrid cooling mechanism, a remarkable decrease PV panel temperature was found. By applying hybrid cooling mechanism to the PV panel, the operating temperature decreased about $11.03 \%$ at average solar radiation of $202 \mathrm{~W} / \mathrm{m}^{2}$. Instead, at same average solar radiation, the operating temperature without applying cooling system keeps in high temperature. High temperature will produce heat energy through PV panel. Moreover, when the average solar radiation increased to $408 \mathrm{~W} / \mathrm{m}^{2}, 616 \mathrm{~W} / \mathrm{m}^{2}, 805 \mathrm{~W} / \mathrm{m}^{2}$ and even $1003 \mathrm{~W} / \mathrm{m}^{2}$, the average operating temperature without applying cooling mechanism increased to $46.39{ }^{\circ} \mathrm{C}, 50.55{ }^{\circ} \mathrm{C}, 52.15{ }^{\circ} \mathrm{C}$ and $56.11{ }^{\circ} \mathrm{C}$ respectively. But when the hybrid cooling mechanism applied to the PV panel, the average operating temperature observed to be decrease with $4.07{ }^{\circ} \mathrm{C}, 5.58{ }^{\circ} \mathrm{C}, 5.02{ }^{\circ} \mathrm{C}$ and $5.77^{\circ} \mathrm{C}$ respectively, at same average solar radiation. The results imply hybrid cooling system have ability as a coolant of PV panel. W. Z. Leow et al. proved that the PV panel temperature can be decreased by applying DC hybrid cooling mechanism on the same type of PV panel through outdoor experimental [18].

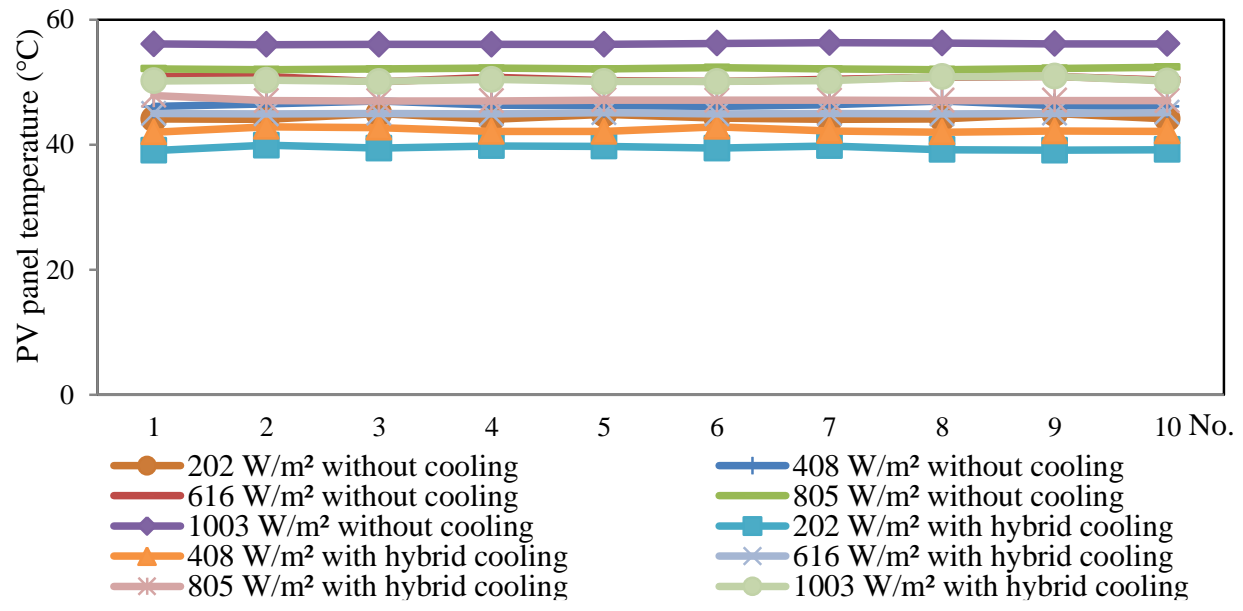

Figure 5. PV Panel Temperature with and Without Hybrid Cooling Mechanism 


\subsection{Electrical Output Performance}

Figure 6 shows the current obtained from both PV panels during experimental were changed in parallel with solar radiation. As the solar radiation increased, PV panel current increased as well. As shown in a figure, without cooling mechanism, the average current output increase with increases of average solar radiation. The minimum current output found at $202 \mathrm{~W} / \mathrm{m}^{2}$ of solar radiation with $1.4 \mathrm{~A}$ while the maximum is at $1003 \mathrm{~W} / \mathrm{m}^{2}$ with 2.49 A respectively. The results were identified the current output when using a cooling mechanism not too much differ compared to without cooling mechanism at same average radiation. The current output only slightly increased when using hybrid cooling mechanism. For instance, at average solar radiation of $805 \mathrm{~W} / \mathrm{m}^{2}$, only $5 \%$ increase in current when using cooling mechanism. It is because the performance of current is not too sensitive to operating temperature. The current output is directly related to the number of photons absorbed by the semiconductor material and thus proportional to solar intensity. With the increase in the incident solar radiation more number of photons will be available to move electrons from balance band to the conduction band resulting in production of more current [19].

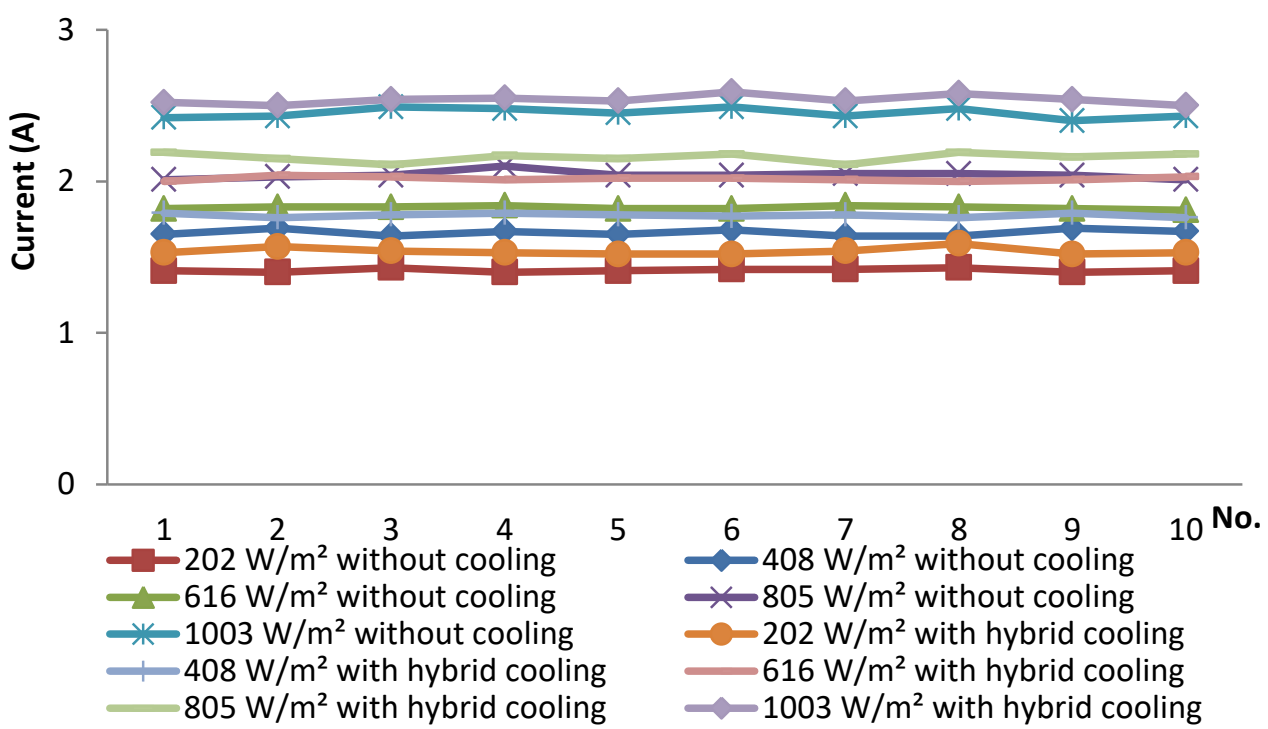

Figure 6. Current Output of PV Panel with and Without Hybrid Cooling Mechanism

The impact hybrid cooling mechanism on voltage output of a PV panel compared with no cooling was observed as shown in Figure 7. Results indicated the average voltage output experiences in decrement value when solar radiation increase. The PV panel voltage is affects most of all of the panel temperature. It decreases with decreasing band gap caused by the increasing in dark current [20]. With an existing hybrid cooling mechanism, the voltage can be increased with a reduction in PV panel temperature as discussed before. By referring to the figure, the average voltage output observed to be increased when using hybrid cooling mechanism. About $6.51 \%$ increase in voltage output found at $202 \mathrm{~W} / \mathrm{m}^{2}$ of solar radiation when hybrid cooling mechanism was applied. By further increasing in average solar radiation, the voltage output observed to be inreased as well. For $408 \mathrm{~W} / \mathrm{m}^{2}, 616 \mathrm{~W} / \mathrm{m}^{2}, 805 \mathrm{~W} / \mathrm{m}^{2}$, and $202 \mathrm{~W} / \mathrm{m}^{2}$ of average solar radiation, the output voltage increase about $7.94 \%, 9.01 \%, 10.97 \%$ and $12.76 \%$ by using hybrid cooling mechanism. Increases in voltage output resulted caused by decrement in PV panel temperature. By referring to the all datasheets produced by PV panel manufacturer, almost all voltage output have negative coefficient in rising temperature. Thereby, hybrid cooling seem to be an efficient method to reduce the PV panel temperature as well as increased the voltage output.

Cooling the PV panel has been performed to determine the influence of reduced temperature under various average solar radiations. Figure 8 presents the power output generated by both PV panel s at 202 $\mathrm{W} / \mathrm{m}^{2}, 408 \mathrm{~W} / \mathrm{m}^{2}, 616 \mathrm{~W} / \mathrm{m}^{2}, 805 \mathrm{~W} / \mathrm{m}^{2}$ and $1003 \mathrm{~W} / \mathrm{m}^{2}$ of average solar radiation. Without applying cooling mechanism to the PV panel, only $23.14 \mathrm{~W}$ of power output can be produced at $202 \mathrm{~W} / \mathrm{m}^{2}$ of average solar radiation. But when attached the hybrid cooling system, the power output increased to $26.94 \mathrm{~W}$. The figure observed the power output of PV panel increase with increases in average solar radiation. The maximum output power found at $1003 \mathrm{~W} / \mathrm{m}^{2}$ solar radiation with $47.08 \mathrm{~W}$. But more output power can be generated by applying hybrid cooling mechanism. The power output increased about $13.83 \%, 12.07 \%, 15.86 \%$ and 
$15.79 \%$ at $408 \mathrm{~W} / \mathrm{m}^{2}, 616 \mathrm{~W} / \mathrm{m}^{2}, 805 \mathrm{~W} / \mathrm{m}^{2}$ and $1003 \mathrm{~W} / \mathrm{m}^{2}$ of average solar radiation. It is clear from the figure that the reduction operating temperature by applying the cooling mechanism the efficient power output of PV panel.

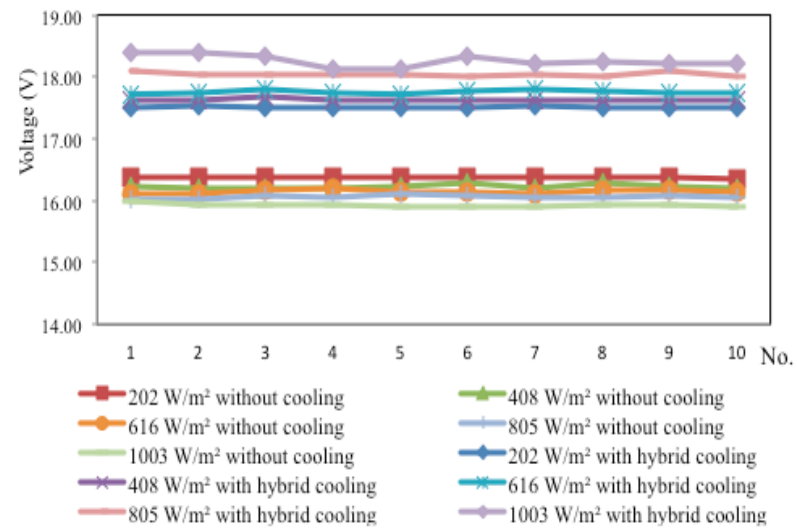

Figure 7. Voltage Output of PV Panel with and Without Hybrid Cooling Mechanism

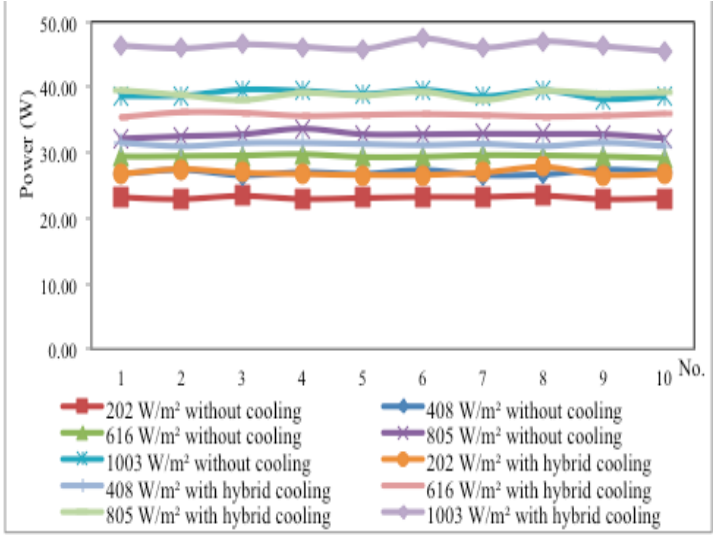

Figure 8. Power Output of PV Panel with and Without Hybrid Cooling Mechanism

\section{CONCLUSION}

A solar simulator using a halogen lamp array as light sources has been tested successfully. The purpose of the existing solar simulator is to analyze the performance of PV panel with and without a hybrid cooling mechanism under steady state condition (indoor testing). Impact of hybrid cooling mechanism observed as reliable method when PV panel exposed to high solar radiation. Solar radiation is one of environmental factor that have an important role in generating a power output of PV panel as well as ambient temperature. By referring from the result produced, high solar radiation with high ambient temperature leads to increase in PV panel temperature. Increment in PV panel temperature leads to a negative impact on performance PV panel. With existing of hybrid cooling mechanism, the PV panel temperature will be decreased, then increased the power output generated.

\section{ACKNOWLEDGEMENTS}

The authors thank the Centre of Excellence for Renewable Energy (CERE) in Kangar, Perlis for providing all data used in this study

\section{REFERENCES}

[1] H. Shahinzadeh, G.B. Gharehpetian, S.H. Fathi, S.M. Nasr-Azadani. Optimal planning of an Off-grid electricity generation with renewable energy resources using the HOMER software. International Journal of Power Electronics and Drive System (IJPEDS). 2015; 6 (1): 137-147.

[2] X. Zhang, J. Shen, P. Xu, X. Zhao, Y. Xu. Socio-economic performance of a novel solar photovoltaic/loop-heatpipe heat pump water heating system in three different climatic regions. Applied Energy. 2104: 20-34.

[3] M.K. Smith, H. Selback, C.C. Wamser, N.U. Day, M. Krieske, D.J. Sailor, T.N. Rosenstiel. Water cooling method to improve the performance of field-mounted, insulated, and concentrating photovoltaic modules. Journal of Solar Energy Engineering. 2014; 136: 49-54.

[4] K.A. Moharram, M.S. Abd-Elhady, H.A. Kandil, H. El-Sherif. Enhancing the performance of photovoltaic panels by water cooling. Shams Engineering Journal. 2013; 4: 869-877.

[5] S. Krauter. Increased electrical yield via water flow over the front of photovoltaic panels. Solar Energy Materials \& Solar Cells. 2004; 82: 131-137.

[6] A.Gaur, G.N.Tiwari. Performance of a Si-thin film PV modules with and without flow: An experimental validation. Applied Energy. 2014; 128: 184-191..

[7] Z. Farhana, Y.M. Irwan, R.M.N. Azimmi, A.R.N. Razliana, N.Gomesh. Experimental investigation of photovoltaic modules cooling system. IEEE Symposium on Computers \& Informatics; 2012.

[8] O. Zogou, H. Stapountzis. Experimental validation of an improved concept of building integrated photovoltaic panels. Renewable Energy. 2011; 36 (12): 3488-3498.

[9] Y T. Minemoto, S. Nagae and H.Takakura. Impact of spectral irradiance distribution and temperature on the outdoor performance of amorphous Si photovoltaic modules. Solar Energy Materials and Solar Cells. 2007; 91: 919-923.

\footnotetext{
Influences of Hybrid Cooling Mechanism through PV System under Solar Simulator Testing (A.R.Amelia)
} 
[10] P. Arjyadhara, Ali S.M, J. Chitralekha. Analysis of solar PV cell performance with changing irradiance and temperature. International Journal of Engineering and Computer Science. 2013; 2 (1): 214-220.

[11] S. Dubey, J.N. Sarvaiya, B.Seshadri. Temperature dependent photovoltaic (PV) efficiency and its effect on PV production in the world- A review. Energy Procedia. 2012; 33: 311-321.

[12] M. Shatat, S. Riffat, F. Agyenim. Experimental Testing Method for Solar Light Simulator with an Attached Evacuated Solar Collected. International Journal of Energy and Environment. 2013; 4 (2): 219-230.

[13] Kohraku S., Kurokawa K. New Methods for Solar Cells Measurement by Led Solar Simulator. Photovoltaic energy conversion. 2003; 2: 1977-1980.

[14] S. Agrawal, S.C. Solanki, G.N. Tiwari. Design, fabrication and testing of micro-channel thermal (MCSCT) tiles in indoor condition. World Renewable Energy Congress (May 2011), Sweeden. 201.

[15] G. Guvench, C. Gurcan, K. Durgin, D.MacDonald. Solar simulator and I-V measurement system for large area solar cell testing. Proceedings of the 2004 American Society for Engineering Education Annual Conference \& Exposition.

[16] Y.M. Irwan, W. Z. Leow, M. Irwanto, Fareq. M, A.R. Amelia, N. Gomesh, I. Safwati. Analysis Air cooling mechanism for photovoltaic panel by solar simulator. International Journal of Electrical and Computer Engineering (IJECE). 2015; 5 (4): 636-643.

[17] Ike, C.U. The effect of temperature on the performance of a photovoltaic solar system in Eastern Nigeria. International Journal of Engineering and Science. 2013; 3 (12): 10-14.

[18] W. Z. Leow, Y. M. Irwan, M. Irwanto, N. Gomesh, I. Safwati. PIC 18F4550 Controlled Solar Panel Cooling System Using DC Hybrid. Journal of Scientific Research \& Reports. 2014; 3 (21): 2801-2816.

[19] A. Sahay, V.K. Sethi, A.C. Tiwari. Fabrication scheme, Instrumentation scheme and Testing of Ground Coupled Central Panel Cooling System (GC-CPCS). International Journal of Current Engineering and Technology. 2014; 4 (2).

[20] P.K. Dash, N.C. Gupta. Effect of Temperature on Power Output from Different Commercially available Photovoltaic Modules. International Journal of Engineering Research and Applications. 2015; 1 (1):148-151. 